\title{
Article \\ Retrospective Cohort Analysis of the Effect of Antimicrobial Stewardship on Postoperative Antibiotic Therapy in Complicated Intra-Abdominal Infections: Short-Course Therapy Does Not Compromise Patients' Safety
}

\author{
Güzin Surat ${ }^{1, *}$, Pascal Meyer-Sautter ${ }^{2}$, Jan Rüsch ${ }^{2}$, Johannes Braun-Feldweg ${ }^{2}$, Christoph-Thomas Germer ${ }^{2}$ \\ and Johan Friso Lock 2 (D) \\ 1 Unit for Infection Control and Antimicrobial Stewardship, University Hospital of Würzburg, \\ 97080 Würzburg, Germany \\ 2 Department of General-, Visceral-, Transplant-, Vascular- and Pediatric Surgery, University Hospital of \\ Würzburg, 97080 Würzburg, Germany; meyer-sautter.p@gmx.de (P.M.-S.); jan-ruesch@t-online.de (J.R.); \\ johannes.braun-feldweg@gmx.de (J.B.-F.); germer_c@ukw.de (C.-T.G.); lock_j@ukw.de (J.F.L.) \\ * Correspondence: surat_g@ukw.de
}

check for

updates

Citation: Surat, G.; Meyer-Sautter, P.; Rüsch, J.; Braun-Feldweg, J.; Germer, C.-T.; Lock, J.F. Retrospective Cohort Analysis of the Effect of Antimicrobial Stewardship on Postoperative Antibiotic Therapy in Complicated Intra-Abdominal Infections: Short-Course Therapy Does Not Compromise Patients' Safety. Antibiotics 2022, 11, 120. https://doi.org/10.3390/ antibiotics11010120

Academic Editors:

Diane Ashiru-Oredope

and Marc Maresca

Received: 22 December 2021

Accepted: 15 January 2022

Published: 17 January 2022

Publisher's Note: MDPI stays neutral with regard to jurisdictional claims in published maps and institutional affiliations.

Copyright: (c) 2022 by the authors. Licensee MDPI, Basel, Switzerland. This article is an open access article distributed under the terms and conditions of the Creative Commons Attribution (CC BY) license (https:/ / creativecommons.org/licenses/by/ $4.0 /)$.

\begin{abstract}
Background: Recent evidence suggests that short-course postoperative antibiotic therapy (PAT) of intra-abdominal infections is non-inferior considering clinical outcomes. The aim of this study was to compare the outcome of short vs. long PAT in complicated intra-abdominal infections (cIAIs) without sepsis. Methods: We performed a single center-quality improvement study at a 1500 bed sized university hospital in Bavaria, Germany, with evaluation of the length of antibiotic therapy after emergency surgery on cIAIs with adequate source control during 2016 to 2018. We reviewed a total of 260 cases (160 short duration vs. 100 long duration). The antibiotic prescribing quality was assessed by our in-house antimicrobial stewardship team (AMS). Results: No significant differences of patient characteristics were observed between short and long PAT. The frequency of long PAT declined during the observation period from $48.1 \%$ to $26.3 \%$. Prolongation of PAT was not linked with any clinical benefits, on the contrary clinical outcome of patients receiving longer regimes were associated with higher postoperative morbidity. AMS identified additional educational targets to improve antibiotic prescribing quality on general wards like unnecessary postoperative switches of antibiotic regimes, e.g., unrequired switches to oral antibiotics as well as prolongation of PAT due to elevated CRP. Conclusion: Short-course antibiotic therapy after successful surgical source control in cIAIs is safe, and long-duration PAT has no beneficial effects.
\end{abstract}

Keywords: antimicrobial stewardship; antibiotic prescribing quality; low-risk intra-abdominal infections; post-operative antibiotic treatment

\section{Introduction}

Antimicrobial stewardship programs (ASPs) are gaining, globally, increasing in merited recognition and acceptance and were primarily launched to stop antimicrobial resistance (AMR) [1,2]. As antibiotic consumption is considered the main driver for AMRnatural factors, such as intrinsic or acquired genetic resistance patterns, environmental sources and missing hygiene measures are contributing effects too-one of the startingpoints includes improving the social and prescribing attitude towards the use of antimicrobial agents [3-6]. Indication, choice of antimicrobial agent, way of application, de-escalation efforts and duration are amongst the markers to be evaluated each time antibiotics are prescribed [7-9]. Incorporating multimodal concepts by engaging the responsible physicians without neglecting nurse staff and undergraduate trainees embedded in a multidisciplinary team, including infectious diseases specialists, microbiologists, pharmacists and infection control physicians in charge, is by far the most worthwhile strategy in order to assure 
sustainable success for AMR to be antagonized [10-13]. Postantibiotic duration for complicated surgical intra-abdominal infections (cIAIs) attracts focus and motivates progressively more data suggesting that a short regimen may suffice for an optimal clinical recovery applying for both, complicated mild / moderate IAIs and severe postoperative IAIs in critically ill patients, provided source control has been achieved [14-16]. Maximizing the clinical benefit by minimizing collateral damage remains the curative principle especially given the high rates of mortality and morbidity in patients with (uncontrolled) cIAIs [17-19]. Uncomplicated IAIs are managed either only surgically or conservatively with antibiotics alone. For cIAIs the approach encloses timely performed surgical source control with appropriate antimicrobial treatment; community or hospital acquired IAIs may be uncomplicated or complicated by definition as well [17,20-22].

This study is to be understood as a sequel to previously published data by Surat et al. on the impact of antimicrobial stewardship on antibiotic consumption for non-elective surgical IAIs [12]. However, this sub-analysis opens the chapter to postantibiotic therapy (PAT) in complicated mild/moderate community-acquired IAIs in non-septic patients with achieved source control, also encompassing de-escalation manners e.g., switching to oral therapy conducted on general wards and aim at confirming the trend that a short duration of PAT is again not afflicted with higher rates of postoperative infectious complications or worse clinical outcomes.

\section{Methods}

This quality improvement study entails a period of 3 years (2016-2018) and was conducted retrospectively in a 1500 bed tertiary hospital in Germany, with an in-hospital ASP officially launched in 2015, gradually reaching out to all departments including the department of general surgery by 2018. The backbone of the in-house AMS team consists of infection control physicians, microbiologists, pharmacists and infectious diseases (ID) consultants with an ID physician responsible for the leadership. The prequel of this project included 776 patients and focused on the impact of antimicrobial stewardship interventions on surgical antibiotic prescription behavior of surgical IAIs, especially postoperative antibiotic use and the appropriateness of indication. The previous analysis revealed a significant reduction of total days of antibiotic therapy and fewer patients receiving PAT altogether [12]. The intention of this subsequent analysis was to assess the impact of antimicrobial stewardship implementations on patients actually receiving PAT due to cIAIs but were non-septic or had life-threatening conditions.

\subsection{Study Design}

The effects of different durations of antibiotic therapy in IAIs were examined by a retrospective cohort analysis. All data were retrieved from the hospital information system and transferred in a pseudonymous database with multiple variables containing baseline patient characteristics, pre-, peri- and postoperative antibiotic therapy (ABT), surgical therapy, and postoperative 30-day outcome. We defined two groups based of the duration of PAT. The short duration group was limited to a maximum of 4 days post-surgery, leant on the STOP-IT trial by Sawyer et al. (sPAT group) [14]. Patients with longer PAT were included in the IPAT group. Any extension beyond this had to be discussed with the inhospital AMS-team. Reasons for allowed extensions of therapy were immune suppression or other present infections such as pneumonia or urinary tract infection. The follow-up was limited to 30 days.

\subsection{Patients}

All patients $\geq 18$ years undergoing emergency abdominal surgery with IAI and PAT during 01.01.2016 and 31.12.2018 were included with the following selection criteria: Diagnosis of peritonitis (ICD-10 K65.0-K65.9), acute cholecystitis (ICD-10 K80.0-K80.01, K81.0), acute appendicitis (ICD-10 K35.2-K35.8), acute diverticulitis (ICD-10 K57.2-K57.22), or intestinal perforation (K25.1-K25.2, K26.1-K26.2, K63.0-K63.2). Patients with the following 
criteria were excluded from analysis: Acute pancreatitis, acute mesenteric ischemia, acute leukemia, end-stage malignant disease in palliative care, ASA score > IV, extra-abdominal infectious focus requiring antimicrobial therapy before and after surgery. For this subgroup analysis, we included only non-septic patients with complicated IAIs with successfully achieved surgical source control. Patients with postoperative anastomotic insufficiency were excluded in this analysis.

\subsection{Outcome Assessment}

Postoperative outcome assessment up to 30 days postoperative. Postoperative complications were graded according to Clavien-Dindo [23]. Clavien-Dindo grade I-II complications were appraised as no severe complications, whereas Clavien-Dindo grade IIIa-V complications were appraised as severe complications. Surgical site infections (SSI) were defined according to the Centers for Disease Control and Prevention (CDC) criteria [24].

\subsection{Statistical Analysis}

All statistical analyses were performed using IBM SPSS Statistics, version 26 (International Business Machines Corporation, Armonk, NY, USA). Descriptive data were reported as means with standard deviation, unless otherwise noted. Groups were compared using the Chi-square, Fisher's exact Test or Mann-Whitney U test according to the data scale and distribution. The level of statistical significance was 0.05 (two-sided).

\section{Results}

\section{Patients' Baseline Characteristics and Indications for Emergency Surgery}

There were no significant disparities in the preoperative risk-stratification between the two groups. Shorter therapies were significantly more common in 2018 than in the previous two years. The collected risk scores (Charlson comorbidity index and ASA score) did not either differ significantly between both groups. Severe previous liver or kidney disease or immunosuppression at the time of surgery were generally rare in the observed cohort and similarly distributed between both groups. Preoperative risk factors such as prolonged hospitalizations or pre-operations were also not present in greater numbers in either group. Intraoperative findings revealed a higher prevalence of peritonitis in the sPAT group (Table 1). There were slightly more cases of cholecystitis in the SPAT, and slightly more cases of appendicitis and colonic perforations in the IPAT group.

Insignificantly more patients (sPAT 50\% vs. 1PAT 38\%) were admitted directly to the normal ward compared to patients who required intensive care support (SPAT $33.8 \%$ vs. IPAT 48\%). Accordingly, these patients were more often postoperatively ventilated (sPAT $21.3 \%$ vs. 1 PAT $31 \%$ ) and received vasopressors (sPAT $17.5 \%$ vs. 1PAT $26 \%$ ). However, these differences were again not statistically significant. There were almost twice as many surgical side infections in the IPAT group (sPAT 6.9\% vs. IPAT 12\%), almost as many as non-intra-abdominal infections (IPAT $11.9 \%$ vs. IPAT 10\%), but this effect was also not statistically significant. Importantly the groups differed significantly regarding postoperative complications. The rate of necessary re-interventions was almost twice as high in long-treated patients (sPAT 15\% vs. IPAT 27\%). Of these re-interventions many had to be performed as re-operations (sPAT $8.8 \%$ vs. 1PAT 23\%). Accordingly, the postoperative complications classified as per Clavien-Dindo were found to be to the disadvantage of the 1PAT group (sPAT 11.9\% vs. IPAT 23\%) (a complication-free course was significantly more frequent in the short treated group (sPAT 36.3\% vs. 1PAT 16\%). Length-of-stay (LOS) differed significantly in the sPAT group (median 7 days) compared to the IPAT group (median 11 days). In contrast, there was no difference in LOIS (Table 2). While the total duration of PAT in the short-treated group was 4 days on average and median, patients in the IPAT group were treated for more than twice as long (median 8; Table 2). 
Table 1. Preoperative patient characteristics and intraoperative findings.

\begin{tabular}{|c|c|c|c|}
\hline \multirow{3}{*}{ Characteristic } & \multicolumn{2}{|c|}{ Patients, No. (\%) } & \multirow[t]{2}{*}{$p$ Value $^{\mathrm{b}}$} \\
\hline & \multicolumn{2}{|c|}{ Postoperative Antibiotic Therapy } & \\
\hline & Short $(n=160)$ & Long $(n=100)$ & \\
\hline 2016 & $42(51.9)$ & $39(48.1)$ & \\
\hline 2017 & $59(59.6)$ & $40(40.4)$ & 0.015 \\
\hline 2018 & $59(73.8)$ & $21(26.3)$ & \\
\hline age, mean (median) & $58.00(61.50)$ & $58.40(62.00)$ & 0.910 \\
\hline \multicolumn{4}{|l|}{ ASA classification } \\
\hline 1 & $15(9.4)$ & $8(8.0)$ & \multirow{4}{*}{0.281} \\
\hline 2 & $77(48.1)$ & $43(43.0)$ & \\
\hline 3 & $58(36.3)$ & $36(36.0)$ & \\
\hline 4 & $9(5.6)$ & $13(13.0)$ & \\
\hline BMI, mean (median) & $27.30(27.00)$ & $27.00(27.0)$ & 0.832 \\
\hline \multicolumn{4}{|l|}{ CCI } \\
\hline none $(0)$ & $41(25.6)$ & $27(27.0)$ & \multirow{4}{*}{0.264} \\
\hline low $(1-2)$ & $33(20.6)$ & $17(17.0)$ & \\
\hline moderate (3-4) & $52(32.5)$ & $25(25.0)$ & \\
\hline severe $(>4)$ & $34(21.3)$ & $31(31.0)$ & \\
\hline liver cirrhosis & $1(0.6)$ & $1(1.0)$ & 0.736 \\
\hline chronic kidney disease & $15(9.4)$ & $17(17.0)$ & 0.069 \\
\hline current immunosuppressive drugs & $9(5.6)$ & $8(8.0)$ & 0.451 \\
\hline community-acquired IAI & $133(83.1)$ & $83(83.0)$ & \multirow{2}{*}{0.979} \\
\hline hospital-aquired IAI & $27(16.9)$ & $17(17.0)$ & \\
\hline high-risk of MDR & $28(17.5)$ & $17(17.0)$ & 0.917 \\
\hline preoperative ${ }^{a}$ LOS, mean (median), $d$ & $14.00(0.00)$ & $13.00(0.00)$ & 0.724 \\
\hline surgery & $15(9.4)$ & $8(8.0)$ & 0.704 \\
\hline MDR & $5(3.1)$ & $5(5.0)$ & 0.444 \\
\hline MRSA & $1(0.6)$ & $0(0.0)$ & \multirow{3}{*}{0.737} \\
\hline VRE & $2(1.3)$ & $2(2.0)$ & \\
\hline 3MRGN & $1(0.6)$ & $2(2.0)$ & \\
\hline intraoperative peritonitis & $90(56.3)$ & $49(49.0)$ & 0.254 \\
\hline gastric perforation & $10(6.3)$ & $4(4.0)$ & \multirow{6}{*}{0.612} \\
\hline small intestine perforation & $10(6.3)$ & $9(9.0)$ & \\
\hline colonic perforation & $20(12.5)$ & $17(17.0)$ & \\
\hline appendicitis & $55(34.4)$ & $39(39.0)$ & \\
\hline cholecystitis & 57 (35.6) & $28(28.0)$ & \\
\hline intestinal obstruction & $7(4.4)$ & $3(3.0)$ & \\
\hline
\end{tabular}

${ }^{a}$ Within 30 days prior index surgery; ${ }^{b} p$ values were derived from Chi-square, Fisher's exact or Mann-Whitney U tests, depeding upon data scale. Abbreviations: ASA, American Society of Anesthesiologists; BMI, body mass index; CCI, Charlson comorbidity index; IAI, intra-abdominal infection; LOS, length of hospital stay; ABT, antibiotic therapy; MDR, multidrug-resistant bacteria, GI: gastrointestinal. 
Table 2. Postoperative outcome.

\begin{tabular}{|c|c|c|c|}
\hline \multirow{3}{*}{ Characteristic $^{a}$} & \multicolumn{2}{|c|}{ Patients, No. (\%) } & \multirow[t]{2}{*}{$p$ Value $^{\mathrm{d}}$} \\
\hline & \multicolumn{2}{|c|}{ Postoperative Antibiotic Therapy } & \\
\hline & Short $(n=160)$ & Long $(n=100)$ & \\
\hline \multicolumn{4}{|l|}{ postoperative transfer to } \\
\hline general ward & $80(50.0)$ & $38(38.0)$ & \multirow{3}{*}{0.069} \\
\hline IMC & $26(16.3)$ & $14(14.0)$ & \\
\hline ICU & $54(33.8)$ & $48(48.0)$ & \\
\hline \multicolumn{4}{|l|}{ postoperative organ support } \\
\hline ventilation & $34(21.3)$ & $31(31.0)$ & 0.077 \\
\hline vasopressors & $28(17.5)$ & $26(26.0)$ & 0.100 \\
\hline SSI & $11(6.9)$ & $12(12.0)$ & 0.157 \\
\hline other postoperative infections ${ }^{b}$ & $19(11.9)$ & $10(10.0)$ & 0.640 \\
\hline re-intervention necessary & $24(15.0)$ & $27(27.0)$ & 0.018 \\
\hline re-operation necessary & $14(8.8)$ & $23(23.0)$ & 0.001 \\
\hline \multicolumn{4}{|l|}{ postoperative findings } \\
\hline MDR & $4(2.5)$ & $3(3.0)$ & 0.809 \\
\hline \multicolumn{4}{|l|}{ postoperative complications ${ }^{\mathrm{C}}$} \\
\hline none & $58(36.3)$ & $16(16.0)$ & \multirow{3}{*}{0.001} \\
\hline no severe complications & $83(51.9)$ & $61(61.0)$ & \\
\hline severe complications & 19 (11.9) & $23(23.0)$ & \\
\hline postoperative mortality & $2(1.3)$ & $0(0)$ & 0.262 \\
\hline LOS mean (median) & $10.00(7.00)$ & $14.00(11.00)$ & $<0.001$ \\
\hline LOIS mean (median) & $2.00(1.00)$ & $3.00(1.00)$ & 0.138 \\
\hline duration of PAT mean (median) in days & $4(4)$ & $9(8.5)$ & $<0.001$ \\
\hline
\end{tabular}

${ }^{a}$ Within 30 days after the index surgery; ${ }^{\mathrm{b}}$ non-intraabdominal infection such as urinary tract infection, pneumonia, etc; ${ }^{\mathrm{c}}$ according to the Clavien-Dindo classification; ${ }^{\mathrm{d}} p$ values were derived from Chi-square, Fisher's exact or Mann-Whitney U tests, depeding upon data scale. Abbreviations: IMC, intermediate care unit; ICU, intensive care unit; SSI, surgical site infection; MDR, multi-drug-resistance bacteria discovered postoperative; PAT, postoperative antibiotic therapy; AMS, antimicrobial stewardship; LOS, length of stay; LOIS, length of stay on ICU.

The initial empiric antibiotic regimens between both groups were quite similar. Patients on long therapy were more frequently subject to switches (sPAT $19.4 \%$ vs. IPAT $56 \%$ ). Switches were rarely due to AMS recommendations in either group (sPAT 9.7\% vs. IPAT $1.8 \%$ ), nor to keeping with the actual resistograms. Undocumented indications for the use of antibiotics were still high (sPAT 77.4\% vs. IPAT 72.7\%; Table 3). Nevertheless, most indications were deemed appropriate by our in-house AMS-team (sPAT 75.6\% vs. IPAT 77\%). Inappropriate indications were mostly due to prolongations of the perioperative prophylaxis (PAP). There were large differences in the management of switches, for example $32 \%$ of those treated long were incorrectly escalated (mostly from a 1st/2nd generation cephalosporin to an oral 3rd generation cephalosporin, in comparison to $9.4 \%$ in the short-treated group (Table 3). As per general definition a switch form intravenous to oral antibiotic therapy is considered de-escalation, we defined this step as 'escalation' when the selected oral antibiotic belonged to 3rd generation cephalosporins such as cefpodoxime [7]. 
Table 3. Postoperative antibiotic therapy.

\begin{tabular}{|c|c|c|c|}
\hline \multirow{3}{*}{ Characteristic } & \multicolumn{2}{|c|}{ Patients, No. (\%) } & \multirow[t]{2}{*}{$p$ Value $^{\mathrm{a}}$} \\
\hline & \multicolumn{2}{|c|}{ Postoperative Antibiotic Therapy } & \\
\hline & Short $(n=160)$ & Long $(n=100)$ & \\
\hline \multicolumn{4}{|l|}{ Initial Regimen: } \\
\hline cephalosporins & $76(72.4)$ & $52(67.5)$ & \multirow{3}{*}{0.641} \\
\hline broad-spectrum penicillin & $26(24.8)$ & $21(27.3)$ & \\
\hline carbapenems & $3(2.9)$ & $4(5.2)$ & \\
\hline switch of antibiotic agent & $31(19.4)$ & $56(56.0)$ & $<0.001$ \\
\hline $\begin{array}{l}\text { postoperative day of switch, mean } \\
\text { (median), d }\end{array}$ & $3.00(2.00)$ & $4.00(3.00)$ & 0.004 \\
\hline \multicolumn{4}{|l|}{ Reason for Switch of Antibiotic Agent } \\
\hline not documented & $24(77.4)$ & $40(72.7)$ & \multirow{3}{*}{0.123} \\
\hline resistogram & $4(12.9)$ & $14(25.5)$ & \\
\hline AMS council & $3(9.7)$ & $1(1.8)$ & \\
\hline switch in ICU or IMC & $7(22.6)$ & $9(16.4)$ & \multirow{2}{*}{0.567} \\
\hline switch on general ward & $24(77.4)$ & $46(83.6)$ & \\
\hline \multicolumn{4}{|l|}{ Assessment Based on AMS-Guidelines } \\
\hline PAT necessary & $121(75.6)$ & $77(77.0)$ & 0.800 \\
\hline de-escalation or discontinuation correct & $154(96.3)$ & $79(79.0)$ & \multirow{3}{*}{$<0.001$} \\
\hline missing de-escalation & $4(2.5)$ & $20(20.0)$ & \\
\hline missing escalation & $2(1.3)$ & $1(1.0)$ & \\
\hline \multicolumn{4}{|l|}{ Switch of Empirical Antibiotic Therapy } \\
\hline not required or correctly performed & $143(89.4)$ & $65(65.0)$ & \multirow{3}{*}{$<0.001$} \\
\hline wrong de-escalation & $2(1.3)$ & $3(3.0)$ & \\
\hline wrong escalation & $15(9.4)$ & $32(32.0)$ & \\
\hline \multicolumn{4}{|l|}{ efficacy } \\
\hline not effective against strains & $96(60.0)$ & $57(57.0)$ & \multirow{2}{*}{0.632} \\
\hline effective against detected strains & $64(40.0)$ & $43(43.0)$ & \\
\hline \multicolumn{4}{|l|}{ Biochemical Values After PAT } \\
\hline leukocytes. mean (median) & $9.60(8.60)$ & $10.20(9.90)$ & 0.076 \\
\hline CRP mean (median) & $10.30(8.00)$ & $6.10(4.00)$ & $<0.001$ \\
\hline PCT mean (median) & $6.90(0.80)$ & $0.50(0.50)$ & 0.643 \\
\hline
\end{tabular}

\section{Discussion}

In this retrospective single-center study we analyzed patients requiring emergency surgery for complicated IAIs over 2016-2018 with attention on the length of PAT. Yet, unlike to the prequel published by Surat et al. these findings included only non-septic patients with adequate source control [12,25]. This time the prescribing attitudes of surgeons on general wards were the focus of our observations, within the wider ambition of discerning the influence of biochemical inflammation markers such as C-reactive protein (CRP) or procalcitonin (PCT) on the duration of PAT. 
In accordance with the data released on postsurgical antimicrobial management in complicated community acquired (or healthcare associated IAIs) so far, our results support that shortened PAT is not associated with worse clinical outcomes. The surgical and clinical conditions that warranted interventions in this study were similar to the general published data (e.g., peritonitis, appendicitis, cholecystitis) [14,15,26-28]. Here, both groups did not differ in the risk-profile and yet the long-duration arm became evident with a significantly higher rate of infectious complications and, in consequence necessitated more re-operations. Continuing misuse of antibiotics has been linked with avoidable adverse events, emergence of antibiotic resistance and unnecessary monetary burden for the health system and demands a change in the prescribing culture of antibiotics $[9,29]$. The debate about the duration of PAT is still ongoing and remains an important key factor for ASPs to target on for it is deemed to being the main reason for inappropriate use of antibiotics in managing IAIs [20,30]. Fortunately, our results re-emphasize the role of ASPs on antibiotics for the postsurgical therapy of complicated IAIs: over the observed three years (2016-2018) the duration of PAT successively shortened, which is mainly attributed to the roll-out of our in-hospital ASP involving general wards in the already regularly happening antibiotic ward rounds and discussions in intensive care units. Although this finding was not statistically significant, long-duration PAT, on the other hand, did not prevent the significant need for re-interventions, even given the fact that PAT was administered twice as long within the long-duration group. These results are in line with data from Tellado et al. that showed that inappropriate indication for the empiric use of antibiotics was associated with unsuccessful outcomes and a higher rate of e.g., re-operations [31].

Looking further into the quality of antibiotic utilization, the long-duration group happened to have not only a higher rate of switches of the empirically selected antibiotic agents, but these switches mainly took place on the general surgical wards resulting in 'escalations' to oral antibiotics-reasonable, one might think given patients surgical and clinical status and the fact that AMS consultations for general wards were missing at the time. Although intravenous to oral antibiotic switch is a main tool in ASPs, in our study these actions were considered inappropriate by our in-hospital AMS team for it prolonged unnecessarily the duration wherein treatment could have been stopped. Importantly, the choices of oral antibiotics were not in keeping with the in-house AMS de-escalation standards (2nd- and 3rd-generation cephalosporin with poor oral bioavailability lacking efficacy; data not available in the result part) $[7,9,28]$.

Guiding antibiotic therapy by inflammatory markers (e.g., leukocyte count, CRP, PCT or interleukin 6), has been numerously investigated in hospitalized patients including those critically ill. PCT carries more specificity and sensitivity in the detection of truly bacterial infections and the guidance of antibiotic duration by PCT may result in significant reduction of antibiotic consumption and mortality [32-36]. Data on the prescribing behavior in cIAIs directed by named markers remain sparse and yet the results, so far, attest PCT a useful tool for both the diagnosis of bacterial infections and discontinuation of antibiotics; yet, it must be stressed that biomarkers should not be read outside the clinical setting $[35,37,38]$. The power and the nature of this study does not allow to draw a conclusion regarding the role of PCT in terms of ceasing PAT or the safeness of such a course, yet following the decrease of the CRP level was associated with longer PAT.

Discussing the results of this study on the whole, the point of its research nature as in the meaning of monocentric and retrospective limits their interpretation. Furthermore, the power of the study cannot be used to reason that shortened duration of PAT is associated with improved outcomes, but it clearly suggests that a longer duration of antibiotic therapy is tied with more complications and does do more harm than good. The subject of the influence of laboratory markers on the duration of PAT and the detailed appropriateness and quantification of switches from intravenous to oral antibiotics will be outlined in future investigations. In conclusion, our results confirm that short-course antibiotic therapy after successful surgical source control in cIAIs is safe. 
Author Contributions: All authors significantly contributed to the design of the study, the acquisition or interpretation of data. G.S. and J.F.L. wrote the manuscript. P.M.-S., J.R. and J.B.-F. collected and analyzed the data. C.-T.G. contributed to the design of the study and revised the manuscript. All authors have read and agreed to the published version of the manuscript.

Funding: There was no funding for this study.

Institutional Review Board Statement: The analysis was approved by the ethics committee of the Julius-Maximilians University of Würzburg (Ref. 20210505 03).

Informed Consent Statement: Not applicable.

Data Availability Statement: The data presented in this study are available on request from the corresponding author. The data are not publicly available due to European General Data Protection Regulation (GDPR).

Acknowledgments: We all consent to thank Ulrich Vogel for the assistance during design and conduct of the study.

Conflicts of Interest: The authors declare no conflict of interest.

\section{References}

1. Sartelli, M.; Labricciosa, F.M.; Barbadoro, P.; Pagani, L.; Ansaloni, L.; Brink, A.J.; Carlet, J.; Khanna, A.; Chichom-Mefire, A.; Coccolini, F.; et al. The Global Alliance for Infections in Surgery: Defining a model for antimicrobial stewardship-results from an international cross-sectional survey. World J. Emerg. Surg. 2017, 12, 34. [CrossRef]

2. Owens, R.C., Jr. Antimicrobial stewardship: Concepts and strategies in the 21st century. Diagn. Microbiol. Infect. Dis. 2008, 61, 110-128. [CrossRef]

3. Davey, P.; Marwick, C.A.; Scott, C.L.; Charani, E.; McNeil, K.; Brown, E.; Gould, I.M.; Ramsay, C.R.; Michie, S. Interventions to improve antibiotic prescribing practices for hospital inpatients. Cochrane Database Syst. Rev. 2017, 2, CD003543. [CrossRef] [PubMed]

4. Charani, E.; Castro-Sanchez, E.; Sevdalis, N.; Kyratsis, Y.; Drumright, L.; Shah, N.; Holmes, A. Understanding the determinants of antimicrobial prescribing within hospitals: The role of "prescribing etiquette". Clin. Infect. Dis. 2013, 57, 188-196. [CrossRef] [PubMed]

5. Vikesland, P.; Garner, E.; Gupta, S.; Kang, S.; Maile-Moskowitz, A.; Zhu, N. Differential Drivers of Antimicrobial Resistance across the World. Acc. Chem. Res. 2019, 52, 916-924. [CrossRef] [PubMed]

6. Holmes, A.H.; Moore, L.S.P.; Sundsfjord, A.; Steinbakk, M.; Regmi, S.; Karkey, A.; Guerin, P.J.; Piddock, L.J.V. Understanding the mechanisms and drivers of antimicrobial resistance. Lancet 2016, 387, 176-187. [CrossRef]

7. de With, K.; Wilke, K.; Kern, W.V.; Strauß4, R.; Kramme, E.; Friedrichs, A.; Holzmann, T.; Geiss, H.K.; Isner, C.; Fellhauer, M.; et al. AWMF-S3-Leitlinie Strategien zur Sicherung Rationaler Antibiotika-Anwendung im Krankenhaus. Available online: https://www.awmf.org/leitlinien/detail/1l/092-001.html (accessed on 5 March 2019).

8. Tarchini, G.; Liau, K.H.; Solomkin, J.S. Antimicrobial Stewardship in Surgery: Challenges and Opportunities. Clin. Infect. Dis. 2017, 64, S112-S114. [CrossRef]

9. Barlam, T.F.; Cosgrove, S.E.; Abbo, L.M.; MacDougall, C.; Schuetz, A.N.; Septimus, E.J.; Srinivasan, A.; Dellit, T.H.; Falck-Ytter, Y.T.; Fishman, N.O.; et al. Implementing an Antibiotic Stewardship Program: Guidelines by the Infectious Diseases Society of America and the Society for Healthcare Epidemiology of America. Clin. Infect. Dis. 2016, 62, e51-e77. [CrossRef]

10. Majumder, M.A.A.; Rahman, S.; Cohall, D.; Bharatha, A.; Singh, K.; Haque, M.; Gittens-St Hilaire, M. Antimicrobial Stewardship: Fighting Antimicrobial Resistance and Protecting Global Public Health. Infect. Drug Resist. 2020, 13, 4713-4738. [CrossRef] [PubMed]

11. Majumder, M.A.A.; Singh, K.; Hilaire, M.G.; Rahman, S.; Sa, B.; Haque, M. Tackling Antimicrobial Resistance by promoting Antimicrobial stewardship in Medical and Allied Health Professional Curricula. Expert Rev. Anti-Infect. Ther. 2020, 18, 1245-1258. [CrossRef]

12. Surat, G.; Vogel, U.; Wiegering, A.; Germer, C.T.; Lock, J.F. Defining the Scope of Antimicrobial Stewardship Interventions on the Prescription Quality of Antibiotics for Surgical Intra-Abdominal Infections. Antibiotics 2021, 10, 73. [CrossRef]

13. Wang, R.; Degnan, K.O.; Luther, V.P.; Szymczak, J.E.; Goren, E.N.; Logan, A.; Shnekendorf, R.; Hamilton, K.W. Development of a Multifaceted Antimicrobial Stewardship Curriculum for Undergraduate Medical Education: The Antibiotic Stewardship, Safety, Utilization, Resistance, and Evaluation (ASSURE) Elective. Elective. Open Forum Infect. Dis. 2021, 8, ofab231. [CrossRef]

14. Sawyer, R.G.; Claridge, J.A.; Nathens, A.B.; Rotstein, O.D.; Duane, T.M.; Evans, H.L.; Cook, C.H.; O'Neill, P.J.; Mazuski, J.E.; Askari, R.; et al. Trial of short-course antimicrobial therapy for intraabdominal infection. N. Engl. J. Med. 2015, 372, $1996-2005$. [CrossRef]

15. Schein, M.; Assalia, A.; Bachus, H. Minimal antibiotic therapy after emergency abdominal surgery: A prospective study. Br. J. Surg. 1994, 81, 989-991. [CrossRef] 
16. Montravers, P.; Tubach, F.; Lescot, T.; Veber, B.; Esposito-Farese, M.; Seguin, P.; Paugam, C.; Lepape, A.; Meistelman, C.; Cousson, J.; et al. Short-course antibiotic therapy for critically ill patients treated for postoperative intra-abdominal infection: The DURAPOP randomised clinical trial. Intensive Care Med. 2018, 44, 300-310. [CrossRef] [PubMed]

17. Sartelli, M.; Chichom-Mefire, A.; Labricciosa, F.M.; Hardcastle, T.; Abu-Zidan, F.M.; Adesunkanmi, A.K.; Ansaloni, L.; Bala, M.; Balogh, Z.J.; Beltran, M.A.; et al. The management of intra-abdominal infections from a global perspective: 2017 WSES guidelines for management of intra-abdominal infections. World J. Emerg. Surg. 2017, 12, 29. [CrossRef]

18. Sartelli, M.; Catena, F.; Di Saverio, S.; Ansaloni, L.; Malangoni, M.; Moore, E.E.; Moore, F.A.; Ivatury, R.; Coimbra, R.; Leppaniemi, A.; et al. Current concept of abdominal sepsis: WSES position paper. World J. Emerg. Surg. 2014, 9, 22. [CrossRef] [PubMed]

19. Sakr, Y.; Jaschinski, U.; Wittebole, X.; Szakmany, T.; Lipman, J.; Namendys-Silva, S.A.; Martin-Loeches, I.; Leone, M.; Lupu, M.N.; Vincent, J.L.; et al. Sepsis in Intensive Care Unit Patients: Worldwide Data From the Intensive Care over Nations Audit. Open Forum Infect. Dis. 2018, 5, ofy313. [CrossRef] [PubMed]

20. Sartelli, M. A focus on intra-abdominal infections. World J. Emerg. Surg. 2010, 5, 9. [CrossRef]

21. Sartelli, M.; Weber, D.G.; Kluger, Y.; Ansaloni, L.; Coccolini, F.; Abu-Zidan, F.; Augustin, G.; Ben-Ishay, O.; Biffl, W.L.; Bouliaris, K.; et al. 2020 update of the WSES guidelines for the management of acute colonic diverticulitis in the emergency setting. World $J$. Emerg. Surg. 2020, 15, 32. [CrossRef]

22. Solomkin, J.S.; Mazuski, J.E.; Bradley, J.S.; Rodvold, K.A.; Goldstein, E.J.; Baron, E.J.; O’Neill, P.J.; Chow, A.W.; Dellinger, E.P.; Eachempati, S.R.; et al. Diagnosis and management of complicated intra-abdominal infection in adults and children: Guidelines by the Surgical Infection Society and the Infectious Diseases Society of America. Clin. Infect. Dis. 2010, 50, 133-164. [CrossRef] [PubMed]

23. Dindo, D.; Demartines, N.; Clavien, P.A. Classification of surgical complications: A new proposal with evaluation in a cohort of 6336 patients and results of a survey. Ann. Surg. 2004, 240, 205-213. [CrossRef] [PubMed]

24. Mangram, A.J.; Horan, T.C.; Pearson, M.L.; Silver, L.C.; Jarvis, W.R. Guideline for Prevention of Surgical Site Infection, 1999 Centers for Disease Control and Prevention (CDC) Hospital Infection Control Practices Advisory Committee. Am. J. Infect. Control 1999, 27, 97-132. [CrossRef]

25. Singer, M.; Deutschman, C.S.; Seymour, C.W.; Shankar-Hari, M.; Annane, D.; Bauer, M.; Bellomo, R.; Bernard, G.R.; Chiche, J.D.; Coopersmith, C.M.; et al. The Third International Consensus Definitions for Sepsis and Septic Shock (Sepsis-3). JAMA 2016, 315, 801-810. [CrossRef] [PubMed]

26. van den Boom, A.L.; de Wijkerslooth, E.M.L.; van Rosmalen, J.; Beverdam, F.H.; Boerma, E.G.; Boermeester, M.A.; Bosmans, J.; Burghgraef, T.A.; Consten, E.C.J.; Dawson, I.; et al. Two versus five days of antibiotics after appendectomy for complex acute appendicitis (APPIC): Study protocol for a randomized controlled trial. Trials 2018, 19, 263. [CrossRef] [PubMed]

27. van Rossem, C.C.; Schreinemacher, M.H.; van Geloven, A.A.; Bemelman, W.A. Antibiotic Duration After Laparoscopic Appendectomy for Acute Complicated Appendicitis. JAMA Surg. 2016, 151, 323-329. [CrossRef] [PubMed]

28. Sartelli, M.; Coccolini, F.; Kluger, Y.; Agastra, E.; Abu-Zidan, F.M.; Abbas, A.E.S.; Ansaloni, L.; Adesunkanmi, A.K.; Atanasov, B.; Augustin, G.; et al. WSES/GAIS/SIS-E/WSIS/AAST global clinical pathways for patients with intra-abdominal infections. World J. Emerg Surg. 2021, 16, 49. [CrossRef]

29. Duane, T.M.; Zuo, J.X.; Wolfe, L.G.; Bearman, G.; Edmond, M.B.; Lee, K.; Cooksey, L.; Stevens, M.P. Surgeons do not listen: Evaluation of compliance with antimicrobial stewardship program recommendations. Am. Surg. 2013, 79, 1269-1272. [CrossRef] [PubMed]

30. Sartelli, M.; Duane, T.M.; Catena, F.; Tessier, J.M.; Coccolini, F.; Kao, L.S.; De Simone, B.; Labricciosa, F.M.; May, A.K.; Ansaloni, L.; et al. Antimicrobial Stewardship: A Call to Action for Surgeons. Surg Infect. 2016, 17, 625-631. [CrossRef]

31. Tellado, J.M.; Sen, S.S.; Caloto, M.T.; Kumar, R.N.; Nocea, G. Consequences of inappropriate initial empiric parenteral antibiotic therapy among patients with community-acquired intra-abdominal infections in Spain. Scand J. Infect. Dis. 2007, 39, 947-955. [CrossRef]

32. Soni, N.J.; Samson, D.J.; Galaydick, J.L.; Vats, V.; Huang, E.S.; Aronson, N.; Pitrak, D.L. Procalcitonin-guided antibiotic therapy: A systematic review and meta-analysis. J. Hosp. Med. 2013, 8, 530-540. [CrossRef]

33. Harbarth, S.; Holeckova, K.; Froidevaux, C.; Pittet, D.; Ricou, B.; Grau, G.E.; Vadas, L.; Pugin, J. Diagnostic value of procalcitonin, interleukin-6, and interleukin-8 in critically ill patients admitted with suspected sepsis. Am. J. Respir. Crit. Care Med. 2001, 164, 396-402. [CrossRef] [PubMed]

34. Simon, L.; Gauvin, F.; Amre, D.K.; Saint-Louis, P.; Lacroix, J. Serum procalcitonin and C-reactive protein levels as markers of bacterial infection: A systematic review and meta-analysis. Clin. Infect. Dis. 2004, 39, 206-217. [CrossRef] [PubMed]

35. de Jong, E.; van Oers, J.A.; Beishuizen, A.; Vos, P.; Vermeijden, W.J.; Haas, L.E.; Loef, B.G.; Dormans, T.; van Melsen, G.C.; Kluiters, Y.C.; et al. Efficacy and safety of procalcitonin guidance in reducing the duration of antibiotic treatment in critically ill patients: A randomised, controlled, open-label trial. Lancet Infect. Dis. 2016, 16, 819-827. [CrossRef]

36. Spoto, S.; Valeriani, E.; Caputo, D.; Cella, E.; Fogolari, M.; Pesce, E.; Mulè, M.T.; Cartillone, M.; Costantino, S.; Dicuonzo, G.; et al. The role of procalcitonin in the diagnosis of bacterial infection after major abdominal surgery: Advantage from daily measurement. Medicine 2018, 97, e9496. [CrossRef] 
37. Hochreiter, M.; Köhler, T.; Schweiger, A.M.; Keck, F.S.; Bein, B.; von Spiegel, T.; Schroeder, S. Procalcitonin to guide duration of antibiotic therapy in intensive care patients: A randomized prospective controlled trial. Crit. Care 2009, 13, R83. [CrossRef]

38. Schroeder, S.; Hochreiter, M.; Koehler, T.; Schweiger, A.M.; Bein, B.; Keck, F.S.; von Spiegel, T. Procalcitonin (PCT)-guided algorithm reduces length of antibiotic treatment in surgical intensive care patients with severe sepsis: Results of a prospective randomized study. Langenbecks Arch. Surg. 2009, 394, 221-226. [CrossRef] [PubMed] 